This item was submitted to Loughborough's Research Repository by the author.

Items in Figshare are protected by copyright, with all rights reserved, unless otherwise indicated.

\title{
A participative and facilitative conceptual modelling framework for discrete event simulation studies in healthcare
}

PLEASE CITE THE PUBLISHED VERSION

http://dx.doi.org/10.1057/jors.2012.176

PUBLISHER

Taylor and Francis

VERSION

AM (Accepted Manuscript)

PUBLISHER STATEMENT

This is an Accepted Manuscript of an article published by Taylor \& Francis in Journal of the Operational Research Society on 21/12/2017 available online: http://dx.doi.org/10.1057/jors.2012.176

LICENCE

CC BY-NC-ND 4.0

\section{REPOSITORY RECORD}

Kotiadis, Katherine, Antuela A. Tako, and Christos Vasilakis. 2019. "A Participative and Facilitative Conceptual Modelling Framework for Discrete Event Simulation Studies in Healthcare”. figshare.

https://hdl.handle.net/2134/8348. 
This item was submitted to Loughborough's Institutional Repository (https://dspace.lboro.ac.uk/) by the author and is made available under the following Creative Commons Licence conditions.

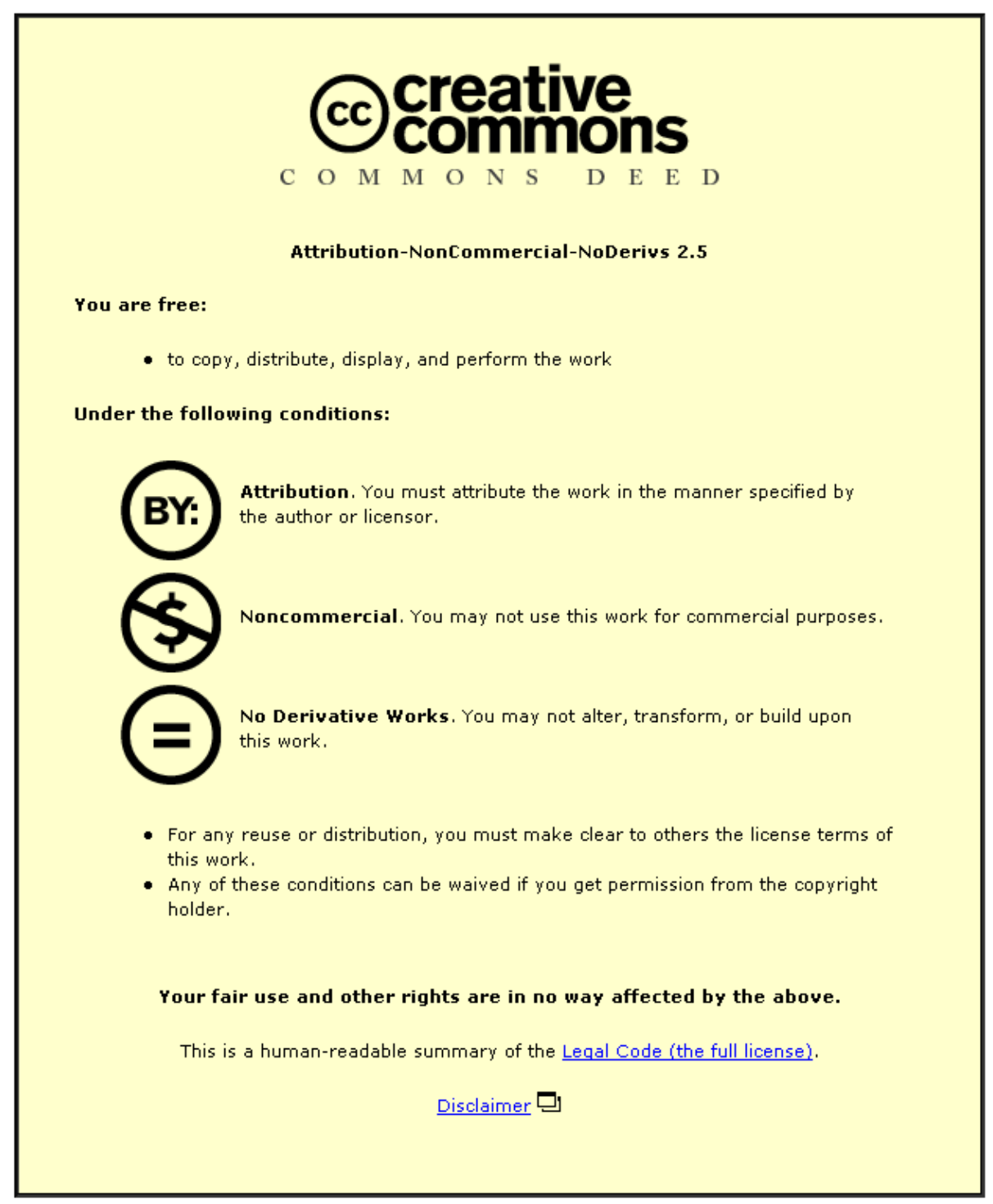

For the full text of this licence, please go to: http://creativecommons.org/licenses/by-nc-nd/2.5/ 


\title{
A PARTICIPATIVE AND FACILITATIVE CONCEPTUAL MODELLING FRAMEWORK FOR DISCRETE EVENT SIMULATION STUDIES IN HEALTHCARE
}

Author names: Kotiadis $\mathrm{K}^{1}$ (University of Warwick), Tako $\mathrm{AA}^{2}$ (Loughborough University) and Vasilakis $\mathrm{C}^{3}$ (University College London)

${ }^{1}$ Warwick Business School, University of Warwick, Coventry CV4 7AL, UK

${ }^{2}$ School of Business and Economics, Loughborough University, LE11 3TU, UK

${ }^{3}$ Clinical Operational Research Unit, University College London, London, WC1H 0BT, UK

\begin{abstract}
Existing approaches to conceptual modelling (CM) in discrete-event simulation (DES) do not formally support the participation of a group of stakeholders. Simulation in healthcare can benefit from stakeholder participation as it makes possible to share multiple views and tacit knowledge from different parts of the system. We put forward a framework tailored to healthcare that supports the interaction of simulation modellers with a group of stakeholders to arrive at a common conceptual model. The framework incorporates two facilitated workshops. It consists of a package including: three key stages and sub-stages; activities and guidance; tools and prescribed outputs. The CM framework is tested in a real case study of an obesity system. The benefits of using this framework in healthcare studies and more widely in simulation are discussed. The paper also considers how the framework meets the conceptual modeling requirements.
\end{abstract}

Keywords: Simulation, Methodology, SSM, Facilitation, Participation, Health Service

\section{INTRODUCTION}

This paper puts forward a framework aimed at supporting the participation of groups of stakeholders in discrete event simulation (DES) studies in healthcare. It supports stakeholder participation during the first stage of simulation modelling, which is often referred to as conceptual modeling.

Discrete event simulation modelling is an established approach in healthcare (June et al, 1999), because of its ability to capture variability yet also explore alternative scenarios through a computer model. However, simulation modellers often face difficulties such as identifying a single problem owner. A study of an organisation with several decision makers with distributed knowledge and power may require the involvement of a client group than a single client. Some DES studies in healthcare (Wilson, 1981; Lowery, 1994; Jun et al, 1999; Fone et al, 2003; Eldabi et al, 2007; Gunal and Pidd, 2005) advocate the benefits of 


\section{Participative and Facilitative conceptual modelling}

involving the users (healthcare administrators and clinicians) in the study. However, existing approaches to the DES modeling process do not support the active participation of a group of stakeholders.

This paper considers how a group of stakeholders can be actively involved during the DES conceptual modelling (CM) process. Conceptual modeling is about deciding what to model and how to model it (Robinson, 2004; Law, 2007). While there is no overall agreement in the simulation community about the role of CM in DES studies (van der Zee et al, 2010; van der Zee et al, 2011) a number of authors prescribe how to undertake CM (Pace, 1999, 2000; Balci and Ormsby, 2007; Robinson, 2008a,b; Kotiadis, 2007).

There is limited guidance on how to develop conceptual models in a participative way involving a group of stakeholders. Van der Zee (2011) puts forward a participative CM approach tailored to manufacturing. However, it is not clear how it can be used to undertake the CM process when involving a group of stakeholders. Therefore there is a need for guidance to support group participation in CM. Guidance for an OR approach can often take the form of a description of a methodology (the principles of a method), a framework (a structure) or technique (a systematic procedure).

This paper contributes to the DES literature a new framework that supports the interaction of a modeller(s) and a healthcare stakeholder group during CM, where stakeholders do not need to be knowledgeable of simulation. The aim of the interaction is to arrive at a common conceptual model. The interaction is largely based around two facilitated workshops dedicated to CM. The framework forms a package that includes: three key stages with two of these involving facilitated workshops; activities and guidance; newly developed and existing tools; prescribed outputs. In addition to the three key stages the framework offers three sub-stages between workshops, during which workshop outputs are consolidated or necessary outof-workshop activities are undertaken. The CM framework was developed for healthcare and tested in a real healthcare study which is described in this paper.

The rest of this paper is structured into five further sections. In the next section we review the literature relevant to participative and facilitative conceptual modelling. Next, we put forward the proposed CM framework and the associated process. Following that we describe a real healthcare case study, where the framework was used to undertake conceptual modelling in practice. We then discuss the benefits and contribution of this framework to healthcare and DES modellers and reflect on how it meets CM requirements. 
Participative and Facilitative conceptual modelling

\section{FACILITATION AND CONCEPTUAL MODELLING}

In this section we start by exploring stakeholder participation and facilitation in the wider OR literature. Following that we consider conceptual modelling, supporting frameworks and evaluation criteria.

\subsection{Stakeholder participation and facilitation in OR}

Stakeholder participation has been shown, in the wider management literature, to lead to a higher rate of implementation of study findings (Nutt, 1986). The benefits of stakeholder engagement in the modelling process have also been highlighted early on in OR studies (Blackett, 1950). Ackoff (1979) suggests that OR interventions should be participative by involving those affected by it. Franco and Montibeller (2010) report a number of benefits from group participation in the OR modelling process such as a mutual understanding of their problematic situation, a strong ownership in the problem formulation and an increased 'buy in' to the process and decisions made.

Currently much of hard OR and simulation is applied in an expert mode which is the opposite to participative and facilitative OR. Expert mode is 'where the operational researcher uses OR methods and models that permit an objective analysis of the stakeholders problem situation, together with the recommendation of optimal (or quasi-optimal) solutions to alleviate that problem situation' (Franco and Montibeller; 2010 p 489). Whereas participative and facilitative OR is where OR methods and models permit the subjective analysis (e.g. many views incorporated) and the operational researcher engages jointly with the stakeholders in the modelling process towards desirable and feasible solutions. The reason for introducing facilitation into OR is that in some situations the expert mode is considered inadequate (Franco and Montibeller; 2010) for reasons such as not being able to achieve agreement among stakeholders about the scope and depth of the problem to be addressed.

Group Model Building (GMB) and Soft Systems Methodology (SSM) are two OR fields that can inform participative and facilitative DES particularly in terms of CM. GMB (Andersen et al, 1997; Rouwette et al 2002; Vennix, 1996, 1999; Vennix and Gubbels, 1992; Vennix et al, 1990) is deemed suitable because of the vast experience in embedding stakeholder participation and facilitation in conceptualising and developing models using system dynamics (SD). The specific techniques and tools used to develop conceptual models in GMB are based on the requirements of SD models, and hence not readily transferrable to a DES study. However, useful insights and advice on preparing for the meetings, the structure of workshop sessions and follow-up activities can be adopted from GMB to fit participative and facilitative conceptual modelling for DES.

SSM, on the other hand, is amenable to stakeholder engagement (Checkland and Scholes, 1999) and facilitation (Franco and Montibeller, 2010) and some initial efforts have been undertaken to embed it to CM in 


\section{Participative and Facilitative conceptual modelling}

DES studies (Kotiadis 2007). SSM is a problem structuring method, considered suitable for understanding a problematic situation (Checkland, 1999). In contrast to traditional 'hard' OR approaches, SSM can deal with unstructured problems characterized by multiple actors, multiple perspectives, conflicts of interest, major uncertainties, and significant unquantifiable factors making it amenable to genuine participation (Checkland, 1999; Mingers and Rosenhead, 2004). For the same reasons it is considered useful to use for conceptual modelling in simulation given that $\mathrm{CM}$ is about making sense of the situation and defining what should be modelled (Kotiadis, 2007, Kotiadis and Robinson, 2008; Pidd, 2007).

A number of studies use SSM to introduce a participative approach to the DES modelling process (Lehaney and Paul 1994; Lehaney and Hlupic 1995; Lehaney and Paul 1996; Lehaney et al. 1999; Pidd 2007). Most of these studies are applied in healthcare but engagement with clients has been mainly undertaken involving stakeholders on a 'one to one' basis, rather than as part of a group in a workshop-based and facilitated environment.

We next consider the CM process in DES with a view to identifying how participative and facilitative CM can be achieved in DES healthcare studies.

\subsection{Conceptual modelling}

In the DES community there is no general agreement about CM and its role in DES studies (van der Zee et al, 2010; van der Zee et al, 2011). For example some do not include the process of knowledge elicitation as part of CM, but do consider it to be a separate preceding phase in the simulation study life cycle (Balci, 2011; Balci et al, 2008). A number of conceptual modelling (CM) definitions have been put forward in the literature and all are useful in understanding the different views and facets to CM. Some consider $\mathrm{CM}$ an intricate process of reflection and interpretation, moving from the real system through to the computer model (Pritsker, et al, 1989; Banks et al, 2005; Zeigler, 1976). Pidd (1999) sees CM as a process of muddling through that requires more creativity and intuition. According to Robinson (2008a) CM is about abstracting a model from a real or proposed system. This involves knowledge elicitation (or acquisition), which takes place in the form of finding out about the problem situation to arrive at a system description and abstraction (simplification) (Kotiadis and Robinson, 2008). The authors of this paper take on the latter view of conceptual modelling.

In an effort to make the conceptual modelling process more transparent, but to also introduce some discipline for others to follow, the need for frameworks that define the steps and relevant outputs has been highlighted (Robinson, 2008ab; Brooks and Tobias, 1996). For example, Robinson (2008a) defines conceptual modelling as the process of developing a non-software specific description of the computer model. He furthermore puts forward the expected outputs of this process, starting with an understanding of the 


\section{Participative and Facilitative conceptual modelling}

problem situation, to specifying the objectives, inputs, outputs, model content, assumptions and simplifications of the model (Robinson, 2008a). A number of other frameworks have been developed in the literature which aim to guide the CM process in DES studies (Robinson et al, 2011; Balci and Ormsby, 2007; Balci et al, 2008).

Some CM frameworks capture the needs of a particular domain context such as the military domain (Shannon 1975; Pace 1999, 2000; Balci and Ormsby, 2007). Another domain-specific CM framework has been developed by Van der Zee (2007), which borrows decomposition principles from engineering, to support conceptual modelling for simulation in manufacturing. This framework provides a simulation reference model and library of tools that can help the development of conceptual models in a transparent way, to allow for joint understanding and stakeholder participation. However, the study does not provide specific details about how the stakeholders are involved in the process. Involving stakeholders, also known as subject matter experts, in CM is also proposed by Balci and Ormsby (2007). Balci et al (2008) who view that CM takes place at a high level of abstraction do not explain how subject-matter experts can be involved in an interactive abstraction process. Kotiadis (2007) has tailored a CM framework to health care but the process followed does not involve group facilitation. She embedded SSM tools to Robinson's (2004) CM framework to develop a CM of a complex integrated health care system for older people. Therefore none of the CM frameworks tailored to a particular domain can be readily used with a group of healthcare stakeholders.

An issue that preoccupies those studying CM is the quality of the conceptual model developed. Sargent (2008), considers whether a sufficiently valid representation of the real life situation is achieved in the CM outputs developed. Balci (2011) is concerned that modellers do not pay sufficient attention to problem formulation (or problem structuring). He draws attention to the danger of solving the wrong problem, which he defines as the Type III Error (Balci, 2010). He furthermore suggests that it greatly affects the acceptability and credibility of simulation application results. Robinson (2008a, b) also considers the qualitative criteria by which to judge conceptual modelling and comes up with a set of four requirements based on criteria put forward by other modellers (Pritsker 1986; Henriksen 1988; Nance 1994; Willemain 1994; Brooks and Tobias 1996; van der Zee and van der Vorst, 2005). These are: validity, credibility, utility and feasibility (Robinson 2008a, b).

- Conceptual model validity is the modellers' perception that the conceptual model is a sufficiently accurate representation of the problem situation to be developed into a computer model for the purpose at hand (Robinson, 2008a). 


\section{Participative and Facilitative conceptual modelling}

- Credibility is a perception from the client's point of view that the conceptual model is good enough to be developed into a computer model that is sufficiently accurate for the purpose at hand (Robinson, 2008a). According to Brade (2004) the credibility of a model concerns 'the perceived suitability and the perceived correctness of all intermediate products created during model development' (p.29). This implies that throughout the CM process, each output should lead to an increase in the client's level of credibility towards the conceptual model.

- Utility is a perception from both the modellers and clients that the conceptual model can be developed into a computer model that can assist with decision making in the particular problem situation (Robinson, 2008a).

- Feasibility is a perception from both the modellers and clients that the conceptual model can be developed into a computer model whilst recognising any project limitation such as time, resources and data availability (Robinson, 2008a).

Besides quality there are other concerns for the CM process such as creativity (Pidd, 2007; Kotiadis, 2007). Creativity is considered to encompass 'seeing a problem in an unusual way, seeing a relationship in a situation that other people fail to see, ability to define a problem well, or the ability to ask the right questions' (Büyükdamgaci, 2003, pp 329). However, being creative on an individual level is difficult because by nature the brain is 'hard wired' by its inherent abilities and predispositions (personality type), as well as the individual's past experience to function in a particular way (Büyükdamgaci, 2003). Group involvement in CM has the potential to stimulate creativity as many personalities are brought together with different knowledge and experience.

\subsection{Summary on the need for introducing facilitation in CM}

In summary, stakeholder participation and group facilitation in CM has the potential to benefit simulation studies in healthcare, because such settings require simulation modellers to engage with stakeholders from different parts of the system. The existing CM frameworks found in the literature do not focus enough on stakeholder participation (van der Zee et al, 2010) with the degree and mode of involvement lacking attention. There is also ambiguity about what CM involves, the process that should be followed and the final outputs derived (van der Zee et al, 2011). Therefore, it is considered important that CM frameworks define the underlying stages (processes), activities that support each stage as well as the resulting outputs (van der Zee et al, 2011). Such considerations would be useful to the practice of conceptual modelling in general and its applications in domains such as healthcare. 


\section{Participative and Facilitative conceptual modelling}

In response to this need for CM, we develop a participative and facilitative Conceptual Modelling framework for DES studies in healthcare. We next describe this framework in more detail.

\section{A PARTICIPATIVE AND FACILITATIVE FRAMEWORK FOR CONCEPTUAL MODELLING IN HEALTHCARE}

\subsection{Introduction to the proposed framework}

The proposed CM framework supports the involvement of a group of healthcare stakeholders in the CM process so that a common conceptual model is reached. The CM process followed is led by the modeller or modelling team, who take on the role of the facilitator. More specifically the interaction between the modeller(s) and the group of stakeholders is supported by the framework, which takes the form of a 'package'. The 'package' includes: stages, activities, tools and deliverables (outputs). This framework (table 1) consists of three main stages (1, 2, 3 in table 1) and three sub-stages (1.a, 2.a and 3.a in table 1), each having a specific purpose. Stages 2 and 3 involve facilitated workshops with the group of stakeholders.

During the workshops, the group of stakeholders is led by a facilitator through dedicated workshop activities. Two types of activities are prescribed, those that support the CM process and those that support the facilitation of the group of stakeholders (table 1). Some activities are also undertaken in between workshops (sub-stages 1.a, 2.a and 3.a in table 1). For example, the modelling team reports back to the stakeholders the deliverables agreed in the workshops, seeking for further reflections and clarifications.

Table 1 about here

For each stage there are tools accompanied by scripts (guidance), which are aimed at supporting the modelling team in achieving the dedicated deliverables (outputs) (table 1). The tools include SSM tools either as they are (e.g. CATWOE and root definition) or tools adapted from SSM for DES (e.g. PMM (Kotiadis, 2007)). These tools have been adapted with language suitable to healthcare (e.g. care system model is SSM's purposeful activity model), but also re-designed to enable the development of respective outputs as part of a facilitated workshop. Other tools have been also developed to support knowledge acquisition and encourage expression of multiple views during and before the workshops (e.g. information collection tool in table 1).

In addition to borrowing tools from SSM, the proposed framework has also borrowed ideas from Robinson’s (2004; 2008a) CM framework and GMB (Andersen et al, 1997; Vennix, 1999,Vennix and Gubbels, 1992; Vennix et al, 1990). Robinson’s (2004; 2008a) framework has influenced our choice of the frame- 


\section{Participative and Facilitative conceptual modelling}

work stages because it incorporates knowledge elicitation for understanding the problem situation as part of conceptual modelling. This coincides with our view of CM. GMB has been a source of influence with respect to considering the idea of workshops and activities to support these stages, particularly in terms of pre and post workshop activities. GMB has also influenced us in the design of project team roles (described in section 3.2).

The main novelty of this framework is the sum of its individual parts, that is the package consisting of stages, activities, tools and outputs that support participative and facilitative conceptual modelling in healthcare. The modeller(s) is supported through the CM structure provided, but also guided in the facilitated element of the process. The aim is to encourage the group of healthcare stakeholders to express their views and provide information, yet be led to a common conceptual model that meets their collective needs. Using the tools provided in a facilitated mode is novel to the DES field, which we believe can support undertaking facilitated CM.

We next put forward guidance relevant to the organisation of workshops and group participation of stakeholders, followed by an explanation of the stages involved in the proposed framework.

\subsection{Stakeholder participation and facilitation in the proposed framework}

\section{The roles of the project team}

An important aspect of the proposed framework is the setup of the different roles as adopted by those taking part in the intervention, forming the project team. These roles are briefly described in table 2 . We distinguish two teams: the modelling and stakeholder team. The modelling team comprises of the simulation modeller(s), the facilitator and the recorder (a note keeper). As a group, they manage the process and stakeholders' expectations, but also encourage participation. Although the facilitator role and the modeller roles can coincide (the same person); one member of the modelling team will always be needed to record the information during the workshop (the recorder). Hence the modelling team could consist of as few as two individuals.

The stakeholder team will typically include subject matter experts, who have an involvement in the organisation or institution of interest, where we identify the following roles: project champion, key stakeholders and other stakeholders. Stakeholder group composition - such as personality types and education - and group size are influential factors in facilitated workshops (Papamichail et al, 2007). Grinyer (2000) warns against larger group sizes and Phillips and Phillips (1993) suggest sizes of less than 12-14. The experience of the authors of this paper coincides with these views for this CM framework. Ideally no more than 


\section{Participative and Facilitative conceptual modelling}

about twelve stakeholders in total or only key stakeholders should be invited in the facilitated workshops to ensure ease of communication for all participants. Involving key stakeholders in the study enables a broader level of ownership of the simulation study and its results within the organization (Robinson, 2008a).

Table 2 about here

\section{The organisation of facilitated workshops}

A facilitated workshop is a gathering of a group of stakeholders (usually face to face) that take part in an active process of exploration guided by a facilitator or a group of facilitators. The amount of time participants spend in a workshop can typically vary from an hour to a full working day. In our experience of dealing with particularly busy health care practitioners, we tend to confine workshops between two to three hours long.

Providing a comfortable environment is considered important in facilitation (Mingers and Rosenhead, 2004). Therefore as part of the workshop organisation issues such as scheduling breaks, the availability of refreshments, room seating, the availability and use of equipment such as a flip chart, a computer projection screen, should be considered and resolved in advance. Good facilitation practices should be considered by the modelling team (Rosenhead and Mingers, 2001).

\subsection{The proposed CM framework's stages}

Each stage in table 1 will be now explained, referring to supporting activities (to CM and facilitation), tools and CM deliverables, coupled with some general guidance and good practice as established from our experience of applying the proposed framework. For interested readers the tools and associated guidance (manuals) are available in a more detailed format on request by the authors. The framework and tools were developed prior to being trialled in a real life case study, with amendments found to be only necessary to the guidance. An example of the CM package in practice will be described in section 4 .

\section{Stage 1: Initiating the simulation study}

The study is initiated with this stage, which aims to set the necessary basis for the development of the study. The modelling team attend informal meetings, one-to-one interviews or undertake on-site observations in order to gain a preliminary understanding of the situation. The activities undertaken are mainly aimed at addressing information needs with regards to understanding the problem situation, roles of stakeholders involved in the system and their opinions about what can be improved. These are collected in the dedicated Information Collection Tool. Furthermore, stakeholders are identified to be invited to the 


\section{Participative and Facilitative conceptual modelling}

subsequent workshops. This in turn, can ensure a successful start, but also a seamless execution of the study. The importance of the initiation stage has been also acknowledged in group model building (GMB) (Vennix, 1999; Andersen et al, 1997).

\section{Stage 1.a: Pre-workshop 1 activities}

Prior to workshop 1, the modelling team can optionally use the information extracted in the Information Collection tool to develop preliminary materials for the tools, which can be used in the first facilitated workshop (described below). Jumping straight into a workshop without any preliminary materials can be time-consuming and unproductive. This has been also emphasized by Vennix (1996) who reports that putting a preliminary model, in front of the group, can stimulate discussion.

\section{Stage 2: Define system}

The second key stage of the framework (Table 1) aims to achieve a common understanding about the situation of interest and the particular system studied among the modelling and stakeholder team. It takes place in a facilitated workshop environment (Workshop 1) where members of the stakeholder team are invited to participate. If the modelling team have prepared preliminary materials for workshop 1 tools, these can be used to start the discussions and stakeholders are invited to revisit and suggest changes/additions. The facilitator guides the group of stakeholders through a series of activities using the dedicated tools to develop the deliverables. The main group activities undertaken in workshop 1 are next described, referring to the dedicated tools and facilitation guidance.

Brainstorming problem area (s) to be addressed and identify general study objectives: The aim of this activity is to reach to a commonly agreed problem statement through a brainstorming process. In initiating the activity, the facilitator invites participants to express their opinion with regards to the question: 'What are the major uncertainties or issues you would like quantitative information about, in order to support your planning and decision making?' Summary points of issues (or problems) voiced are written on a flipchart (visible to all) by the facilitator or any other member of the modelling team. The facilitator plays an important role in making sure that priorities are put forward as well as highlighting those problems that are unlikely candidates for a simulation study. This involves encouraging divergent thinking - thinking through and articulating different perspectives of the problem - before moving to convergent thinking forming a consolidated perspective of the problem - (Franco and Montibeller, 2010). By the end of this activity an agreement as to the issue (s) (general study objectives) which should be pursued through the study, should be reached. If the stakeholders do not agree on the most important problem to be pursued by the study within the timeframe for this activity, then the facilitator considers negotiation. This can be achieved by either asking individual stakeholders to attach a level of importance according to a rating 


\section{Participative and Facilitative conceptual modelling}

scale for the different problems raised. As a last resort the facilitator can consider concealed or open voting. At the end of this part of the group interaction the ownership of the problem (at least acknowledgement) moves away from the study initiator or facilitator into the hands of the workshop participants. It also serves as an opportunity for the facilitator to get to know the stakeholders and their opinions.

Define system boundaries: The situation of interest as expressed by the group in the previous activity is now further explored utilizing SSM tools such as, the CATWOE (a mnemonic that represents the first letter of each system element: Customers, Actors, Transformation process, World view, Owners and Environmental constraints), root definition (a definition of the system of interest in the form of, do X by using Y to achieve Z) and care system model (an adaptation of the Purposeful Activity Model - PAM) (Checkland, 1999). The benefit of using SSM in this stage lies in that it provides useful tools that "make[s] the thinking process coherent and capable of being shared" (Checkland and Scholes, 1999, pp. $67)$.

Developing the CATWOE and root definition serves as a warm-up exercise to help stakeholders focus on the relevant elements of the situation and thus drawing a boundary around the problem. This sets the scene for developing the next tool, the care system model that is a graphical representation of the key activities occurring in the care system of interest. The process of developing a Care System Model (CSM) consists of collecting the verbs that describe the activities that take place in the care system, based on the logical dependencies involved (Checkland and Scholes, 1999). We group the key activities that take place in healthcare systems, into three generic categories: clinical, managerial and research. These three categories are not put forward in the standard SSM literature. We have adapted this tool and renamed it to fit problem situations in health. The clinical part can be a closer representation to the computer model, depending on the problem situation studied (Kotiadis and Robinson, 2008). Whereas, the research and managerial parts of the CSM will enrich the understanding of the clinical needs leading to a better model.

While the SSM tools such as CATWOE, root definitions are explained in detail in Pidd (2007) and Checkland and Scholes (1999), the reader is not guided on how these tools can be used in a facilitated workshop environment. In this approach dedicated forms can be used by stakeholders in order to engage in the process and also to keep notes. These are provided by the facilitator in the workshop. The facilitator can find guidance and tips in the accompanying manual for the framework, such as questions to be directed to the participants while using the tools. An extract of the guidance provided for using the CATWOE tool as part of the proposed CM framework is provided in Figure 1 below.

Figure 1 about here

\section{Stage 2.a: Post workshop 1 and Pre-workshop 2 activities}




\section{Participative and Facilitative conceptual modelling}

The presentations of the tools and information collected can be re-arranged after the workshop (sub-stage 2.a), i.e. re-order the activities and links in CSM to convey a sensible flow. The outputs of this first workshop, including the general study objectives, CATWOE and CSM are disseminated to stakeholders for comments. This is part of the on-going process of ensuring CM output validity. In the meanwhile, preparations for the second workshop can optionally commence, by developing preliminary materials for workshop 2.

\section{Stage 3: Specify conceptual model}

In the third stage, a second facilitated workshop with the same group of stakeholders takes place, where more detailed elements of the conceptual model are identified. The group activities part of this stage as presented in Table 1, will be next explained as well as the relevant tools used to enable stakeholder participation and group facilitation.

Agree the performance measures: This activity aims to identify interactively with stakeholders the measures used to judge the performance of the system to be simulated. A key influence are the three performance criteria (3Es): efficacy, efficiency and effectiveness put forward in SSM interventions (Checkland and Scholes 1999). The dedicated tool, called performance measurement model (PMM) (Kotiadis, 2007), has been adapted so it can be used in a stepwise and interactive process in the workshop. The PMM tool is an organised diagram of interlinked concepts: performance measures, monitoring activities, control activities (activities to determine if action is needed - starting with 'determine if') and action to be taken (changes or improvements to the system to achieve the performance measures specified). These concepts are then linked, in a logical order, using arrows to form a diagram. The process for developing the PMM tool involves asking participants to brainstorm performance measures for each concept separately. A dedicated form explaining and listing the interlinked concepts has been developed to help participants' in their thinking process.

Identify inputs, outputs and model content: The PMM tool is next used to identify three types of simulation model requirements: I for Inputs (experimental factors), O for outputs (model results) and C for model content. This requires knowledge of simulation, hence the modelling team can choose to undertake this activity without stakeholder input during a workshop break. The inputs (I) will be closely related to the action to be taken i.e. improvements to the system. The facilitator and stakeholder team negotiate which inputs and outputs to include in the simulation model. Stakeholders provide an opinion about the inputs as to what range of variation is considered sensible and possible. Whereas for outputs, the facilitator identifies from the stakeholders, what should be the aim for each performance measure. This process exempli- 


\section{Participative and Facilitative conceptual modelling}

fies one of the efforts embedded in the process of maximising the utility and feasibility of the conceptual model.

Define model objectives: This activity requires input from the modelling team although participating stakeholders are encouraged to contribute to the process. This activity can if necessary be undertaken to a large extent during a break by the modelling team. The modelling team can then use the preliminary objectives as a starting point to the stakeholders discussion as a workshop activity. A dedicated tool, in a table format can be used to define simulation study objectives. The tool includes the following components: purpose, target performance, change (optional), constraints (Robinson, 2004). The modelling team may decide to build more than one simulation model if that is necessary to satisfy the stakeholders' needs (objectives), but issues such as data availability, project time lines and the skill of the modellers must be considered.

Produce communicative model: The next workshop activity focuses on agreeing with stakeholders the model contents, scope and level of detail as represented in a communicative model. The tool used in this activity is called patient flow diagram (PFD). It is equivalent to the process flow diagram in DES but aptly named here for health care. While other modellers can choose to use alternative DES diagraming instead, the process flow diagram is considered to be a simple and comprehensible diagrammatic tool for participants with little or no knowledge of simulation modelling (Robinson, 2004). For operational systems in health care, such as patient pathways, the PFD is convenient to use for defining in more detail the flow of activities and rules involved. The practice of developing a PFD with and in front of the stakeholder team provides a forum for discussion, where further abstraction takes place and a communicative model is developed based on the stakeholders' shared mental models of the care system. The PFD can be also produced as an extension of the clinical part of the CSM already developed in the previous stage, by defining in more detail the possible routes that patients follow in the care system. The communicative model, PFD agreed in this workshop, will be subsequently transformed into a computer model by the modeller(s).

Data collection: Discussing the data collection is an on-going activity throughout the workshop. However following the activities of determining the performance measures and drawing the communicative model, it is useful to allocate dedicated time to identify any issues that might impact the quality and availability of data. During this activity, the modelling team negotiate with the stakeholder team the responsibility and timelines for the data collection.

\section{Stage 3.a: Post workshop 2 activities}




\section{Participative and Facilitative conceptual modelling}

Following the workshop (sub-stage 3.a), a report with refined workshop CM outputs can be prepared by the modelling team for the stakeholder group. The report can also include data requirements and the individuals responsible for these. The report details the conceptual model and provides the stakeholder team with the opportunity to reconsider and validate the conceptual model outside the workshop environment.

\section{CASE STUDY: UNDERTAKING CONCEPTUAL MODELLING FOR AN OBESITY SERVICE}

This section provides a first-hand account of applying the proposed participative and facilitative conceptual modelling approach in an obesity care system simulation study. We describe the process followed and provide some of the conceptual model outputs developed in the facilitated workshops. The simulation stages that typically follow CM such as model coding and experimentation are outside the scope of this paper and will not be described.

\subsection{Initiation of the Obesity study}

One to one meetings were initially held with the project champion and the key stakeholder, in addition to on-site observations of various obesity clinics with the purpose of the modelling team getting familiarised with the obesity in general and clinical context. Initial discussions with the project champion and some key stakeholders revealed their interest to look into the resource provision at a London based obesity centre spanning several hospitals. A database with all the information collected was compiled in the Information Collection tool. The information identified at this stage can take the form of facts and figures relevant to the problem. Examples of some facts collected follow. The prevalence of obesity in the UK has more than doubled in the last 25 years (Butland et al, 2007), whereas a quarter of the adult population in England is classified as obese (The NHS Information Centre Lifestyles Statistics, 2009). Obesity is a complex issue, affected by a multitude of factors (National Institute for Health and Clinical Excellence, 2006). Some of the government references we use in this paper were also suggested by the stakeholders when explaining the general obesity problem and were recorded in the information collection tool.

We were also told that the treatment of patients with morbid obesity is increasingly becoming a priority for healthcare services. A number of health care institutions have introduced specific services aimed at its treatment, including lifestyle, medical and surgical interventions. The increasing prevalence of obesity in the UK has resulted in an increased number of patients seeking access to health care services, where the available capacity and resources cannot always meet the increased demand. Indeed, health care institutions providing obesity-related treatment at the time of this research (early 2010) were just about meeting the demand, However in the long term, it is recognised that they would be running the risk of building 


\section{Participative and Facilitative conceptual modelling}

long waiting lists, with patients experiencing long waits. As a result, a number of health care providers (NHS trusts in the UK) risk breaching government directives, such as the 18 week target (patient maximum wait time from referral to first treatment) set by the Department of Health in the UK (Department of Health, 2004).

Also a role analysis was undertaken during this stage and a project champion, representing the health care institution, was assigned. A stakeholder group of around 12 accepted the invitation to participate in the workshops. The stakeholder group consisted of a wide representation of different parts of the obesity care system, including healthcare professionals of different seniority and a range of specialties such as general surgery, chemical biochemistry, anaesthetics, and endocrinology as well as a Medical Director. The participants were affiliated with teaching hospitals in London (England) and were all involved with the treatment of the obese. Some of the participants' position spanned across more than one hospital. The modelling team involved three analysts, who took on different roles, that of the facilitator, modeller, recorder (note keeper) etc. throughout the period of the project.

\section{Pre-workshop 1 activities (stage 1.a)}

The information obtained from the activities undertaken in the initiation stage made it possible for the modelling team to develop some preliminary tools such as CATWOE, root definition and care system model during stage 1.a. These were used in workshop 1 to ensure that the workshop met the objectives in the allotted time.

\subsection{Defining the obesity care system (Workshop 1)}

The workshop was held in a conference facility to provide a more suitable workshop environment and encourage all stakeholders to participate. In hindsight, the power structures were not completely eliminated as at the start of the workshop some more junior doctors and nurses were less forthcoming with their views. Prompting by the facilitator ensured that all stakeholders participated. Towards the end of the workshop the facilitator's challenge was to ensure the conversation was at the centre of the room focussed on producing the outputs rather than among groupings of stakeholders.

As part of the problem statement, the facilitator prompted participants to discuss the problems faced by the service providers. Among others, the key issues discussed that were relevant to a simulation study included the scarcity of resources (doctors, nurses, beds) available for service provision in out-patient clinics and in pre- and post-operative care. The stakeholder team's concerns initially centred around the increasing patient referrals from primary care practices and the resulting increased waiting lists. However, a theme that resonated among the participants was that the system grew over a relatively small period of 


\section{Participative and Facilitative conceptual modelling}

time without proper consideration of its needs and its design. The participants commented on the need for a better understanding of the overall potential of the care system as well as considering change to improve the system.

The preliminary CATWOE brought in the workshop required, as expected, some redevelopment to fit the views of the participants. The participants agreed on the content of some definitions whilst on others lively discussions and negotiations followed until the language was agreed. The agreed CATWOE and root definition can be found in figure 2 .

Figure 2 about here

The CSM was next produced through a brainstorming activity where lively discussions focussed on how their activities map onto their system as defined previously though CATWOE and the root definition. A preliminary model of clinical and managerial activities was prepared before the workshop. Activities were deleted and added as a result of the discussion.

During the process of designing the CSM with the stakeholders, further insights about the problem situation were gained by participants. The facilitator asked participants to consider activities that should be there as well as activities that are already in place. The stakeholders also came up with new ideas regarding the system design such as the introduction of a patient education session which was later introduced in the real system. This exercise also served as means of bringing out some additional problems and inefficiencies involved in their obesity system that had not emerged during the problem statement activity. Concerns were raised regarding inefficiencies present in the care system such as patients wrongly being referred to some clinics resulting in long waiting lists. Stakeholders were then asked to identify interrelations between the three groups of activities (managerial, clinical and research). For example, the managerial activity "Design and set up patient group forum” is connected to the clinical activity "Provide group forum for patients" in Figure 3.

Figure 3 about here

\section{Post workshop 1 and Pre-workshop 2 activities (stage 2.a)}

All the outputs from the activities and tools used were refined post workshops 1 for the purpose of dissemination to the stakeholder team. For example, the CSM was re-arranged into its final format (figure 3) after the workshop, because it was difficult for the modelling team to use a dedicated software to draw the diagram whilst keeping up with the flow of the conversation. After the workshop, the CSM diagram was furthermore validated by the stakeholder and modelling team. 


\section{Participative and Facilitative conceptual modelling}

A report with workshop outputs was sent to the stakeholders for comments. Communications with the project champion and some key stakeholders signalled the need to reduce the scope of the problem to meet the study timeframes. More specifically, some key stakeholders realised that urgent action was needed for one particular service as capacity would soon not meet the accelerating demand for the service. For this reason the study of this particular group of obesity patients treated at a London (UK) hospital was prioritised. The stakeholders' particular interest was to explore how a potential increase in capacity and/or decrease in patient referrals (equivalent to capping the number of patient referrals accepted by the institution of interest) would affect their patient throughput and targets. Therefore, for the remaining of the study, the CM focus funnelled down to a particular London based hospital within the jurisdiction of some of the key stakeholders participating in the first workshop.

This in-between workshop step enabled the stakeholder and modelling team to consider the workshop outputs and decide what was feasible within the study timeframe and useful for their immediate needs. Therefore this provides an example of how this CM framework met the needs of utility and feasibility.

In parallel to workshop dissemination the modelling team also organised and prepared preliminary materials for the second workshop. The second workshop was organised slightly differently to workshop 1 due to stakeholder team's constraints. Workshop 2 took place in a hospital in a meeting room with flip chart and projection facilities. A sub-set of the initial stakeholder team attended. Some of the stakeholders were replaced to tailor the membership to the specific hospital whilst maintaining a wide representation. Seven stakeholders attended workshop 2 .

\subsection{Specifying the conceptual model for the Obesity system (Workshop 2)}

The workshop participants met regularly in a clinical or service planning capacity and it was not difficult for the facilitators to keep the conversation on track or to encourage participation. The group was also smaller in number compared to the first workshop which meant that facilitation was easier.

In this workshop the performance measures were discussed following the process explained in section 3.3. The PMM tool was developed interactively, after showing an example of the PMM (a sort of preliminary model). The reduced number of workshop participants meant that they were all particularly involved in the development of the PMM tool. The PMM was tidied up and validated post workshop (Figure 4).

Figure 4 about here 


\section{Participative and Facilitative conceptual modelling}

The activities in the PMM tool were used to develop the model objectives. For example, the change activities such as increase the number of surgeons, physicians and patient referrals, were transformed into a modelling objective, by linking them to the purpose, target performance and constraints. The objectives were defined in interaction with the stakeholders, although refinements were made after the workshop. The resulting the objectives emerging from the process that had been followed were then verbally agreed. These are displayed in Table 3.

Table 3 about here

Next, the workshop concentrated on drawing the communicative model using the dedicated patient flow diagram (PFD) tool. This mainly involved getting the participants to contribute the flow that patients follow in the obesity care system. Each participant contributed his/her unique knowledge in capturing diagrammatically each part of the patient flow. The facilitator drew the PFD on flip chart paper in front of the stakeholders. The stakeholders interactively instructed the facilitator in the design of the flow diagram. The facilitator ensured that that the resulting diagram was representative of participants' mental perceptions and that they felt that relevant parts of the system were included. The workshop concluded with a discussion on data requirements, considering data availability. The project champion promised to send the data collected to the modeller. Positive feedback was given to the modelling team about the workshop process and achievements in the time frame.

\section{Post workshop 2 activities (stage 3.a)}

Post workshop 2, a report was put together detailing aspects of the problem to be explored in the study and the simulation study objectives specifying the range over which the changes in the inputs were possible. However, the third objective was dropped in order to develop a simpler model in the allotted time frame. Also, the first two objectives were of higher priority to the participants.

The PFD diagram was also tidied up using graphical software (Visio) and included in the report for inspection and reflection on its accuracy and completeness. The final version of the PFD as agreed with the stakeholder team after the workshop is displayed in Figure 5. Dedicated space was provided for the stakeholders to reply to questions regarding data collection and information as well as a space for possible comments. A final report was distributed to the stakeholder team that detailed the outputs/deliverables of both workshops. This formed the conceptual model for the simulation study.

Figure 5 about here

Although the computer model and subsequent stages are not within the remit of this paper, we assure the reader that the computer model and its finding were accepted by the entire stakeholder team. The stake- 


\section{Participative and Facilitative conceptual modelling}

holder team attended two further workshops focussed on experimentation and implementation respectively. The workshop stakeholders provided positive feedback on the process and outputs resulting from it.

Some of the findings of simulation model were implemented during the study itself with others requiring more time for implementation e.g. building a new operating theatre. Another journal paper reports the simulation model and study findings (Tako et al, 2012).

\section{DISCUSSION}

In this section we evaluate the facilitated CM framework by highlighting: a. the potential benefits to healthcare and other studies, b. the potential benefits from the modellers point of view and c. its ability to meet the CM requirements for a framework.

\subsection{Benefits of a facilitative and participative CM framework for healthcare}

The proposed framework 'package' can be used in healthcare settings and other similar contexts that involve multiple stakeholders where different views or even conflict are likely to arise. In the nonhealthcare case, we suggest that some minor adjustments to the healthcare terminology would be needed. Reflecting from our experience, we identify the following benefits from using the proposed framework:

- Supports stakeholder participation in the CM process. The facilitator guides the group through a stepwise process with activities leading to a conceptual model. This is primarily non-technical and it does not require that the stakeholder team to have prior simulation knowledge. In addition various tools and guidance have been adapted to healthcare terminology.

- Encourages plurality of opinions and enables reaching consensus among the stakeholders. The process enables the individual stakeholders to express their different viewpoints and agendas at each stage in the process yet move to a commonly agreed conceptual model. Influenced by PSMs and GMB, the approach entails group processes, including open discussions, reflection points, voting if necessary, etc that make it possible for a group of stakeholders to be involved. Therefore any conflicting opinions arising can be resolved within the workshop. Both the process and the resulting outputs are transparent to the group of stakeholders involved.

\subsection{Benefits of facilitative and participative CM framework for the modelling team}

The main benefit of the proposed framework to a modelling team is the structure provided to the conceptual modelling process and the intermediary activities and tools to achieve the planned outputs. Within workshops the modellers' and stakeholders' time is spent productively undertaking activities that can re- 


\section{Participative and Facilitative conceptual modelling}

sult in the CM outputs. The activities are supported by dedicated tools to ensure that the aims of each workshop are met and CM deliverables are produced within a predetermined amount of time. The CM framework 'package' is expected to be particularly useful to novices in ensuring that a conceptual model (relevant CM deliverables) is achieved.

Another benefit is that the modelling team is also supported in the facilitation activities that are typically foreign to traditional DES practice. This benefit is expected to be useful to healthcare simulation modellers and modellers who need to involve groups in the modelling process. However we caution modellers that in order to learn to apply the framework and tools an initial effort will be required of the modelling team. In our experience considerably less effort is spent in preparing for similar workshops in subsequent studies.

\subsection{Does the framework meet the conceptual modelling requirements?}

CM requirements are likely to be declared slightly differently within the DES community depending on the CM beliefs one holds. As explained earlier in section 2.2 and 2.3 the DES community does not universally agree on the role and therefore breadth of conceptual modelling (add magazine refs). The view held by the authors of this paper is that the role of CM is knowledge elicitation and model abstraction (Kotiadis and Robinson, 2008). Therefore when judging the framework it is necessary to point out that aside from reflecting on the CM quality criteria (Robinson, 2008a) presented in section 2.2 we will also explore if it meets its underlying role of knowledge elicitation and model abstraction.

\section{Knowledge elicitation and abstraction}

The proposed framework supports knowledge elicitation with a number of tools that have been borrowed from SSM or adapted to fit CM needs. SSM as a first step is about understanding the problem situation and has been designed to structure problems taking a softer approach. SSM is particularly useful for messy situations, where the objectives and existing problems are not clear and multiple perspectives exist (Checkland, 1999). This is often the case with problems encountered in health systems, such as our case study.

The framework also supports knowledge elicitation by enabling creativity to take place. The involvement of a group means that the problem is seen from different points of view as expressed by each stakeholder leading to creativity. The process laid out supports a thorough definition of the problem with stages 1 and 2 dedicated towards it. The guidance enables the facilitator to ask a range of sensible questions to support the extraction of information relevant to developing a representative CM, enabling divergent and conver- 


\section{Participative and Facilitative conceptual modelling}

gent thinking ((Franco and Montibeller, 2010). This makes it possible to pay particular attention to problem formulation as suggested by Balci (2011).

Furthermore, we believe that the proposed framework supports abstraction during the CM process because it supports the funnelling down of ideas from the various layers of the system in breadth and depth, using negotiation and consensus to lead to a common description of the conceptual model to the layer that is of most interest to the stakeholders. For example in the obesity case study the wider system was initially considered (workshop 1) before homing in on a particular area of concern in workshop 2. Also the process supports the more traditional view of abstraction by capturing all the components of the conceptual model (e.g. objectives, inputs/outputs and model content) as defined by Robinson (2008) and thus being able to move on to coding. Of course we must differentiate between abstractions supported by the CM process followed described above and abstractions that are forced onto the modelling team. An example of the latter in the obesity case study is the reduction of objectives to build a computer model within the available time frame (section 4.4). We found that this process led to the development of a conceptual model accepted by the stakeholder team, creating in return a buy-in into the CM and the simulation study that followed.

\section{Validity}

The framework supports CM validity in a number of ways. The CM developed is based on the information extracted involving the stakeholders in the workshops or on the additional information requested from the stakeholders in between workshops. The structured contact with stakeholders ensures that the problem is conveyed accurately into a conceptual model, which allows for verification of the conceptual model to take place. At the same time the guidance provided and the intermediate activities and tools, that interweave between the definition of the problem and objectives, can help the modeller to ensure that a valid conceptual model is developed. Furthermore, throughout the CM process the modelling team prepares post workshop documents (as part of workshop outputs), which are then disseminated to the workshop participants. This provides the modelling team with the opportunity to reflect on, amend and validate the outputs outside the workshop. The interaction between stakeholders and modellers helps the modellers gain an accurate picture of the problem situation, which in turn reduces the danger of committing a type III error (Balci, 2010).

\section{Credibility}

The framework supports the creation of CM credibility from the stakeholders point of view by enabling them to partake with the modelling team in the development of the CM outputs. Each positive interaction 


\section{Participative and Facilitative conceptual modelling}

and successful output development reinforces their credibility towards the modelling team and process. In the case study presented, the project champion elicited the opinions of the workshop participants and fed this back to the modelling team. The stakeholders agreed with the workshop outputs prepared, commenting that they were appropriate and met their needs.

\section{Utility}

The framework supports the development of the modellers and stakeholders perception of CM utility which can be deduced from the commitment observed from the stakeholders. The active participation of the stakeholders in the process is reassuring, for the modellers as well as the stakeholders, that the CM produced is useful.

In the case study described in this paper the stakeholders were keen on attending the workshops and attended further workshops beyond conceptual modelling. The majority of the workshops took place at 7 am which indicates the value placed by modellers and stakeholders and their commitment to the process. If they did not believe these workshops and the interaction were useful, they would have not given up their valuable time.

\section{Feasibility}

The framework's in between stages and the opportunities for revisions throughout the CM process helps ensure that both the stakeholders and modellers believe that the resulting conceptual model is feasible. For example in the obesity case study the limitations were discussed and revisions were made to the conceptual model throughout the process. In between the two workshops the modelling team and stakeholders revised the breadth of the problem area to be tackled by the simulation study. This was initiated by the stakeholders. Furthermore, after the workshops, the modelling team held team meetings to consider any emerging coding or data challenges and possible solutions. In the obesity study described, dropping the third model objective mainly for practical reasons, which was accepted and agreed by both the modelling and stakeholder team was a result of considerations of the feasibility of the study.

\section{CONCLUSIONS}

This paper presented a participative and facilitative conceptual modelling framework developed for DES in healthcare. The framework consists of three key stages and three sub-stages of which two involve workshops attended by a team of stakeholders. These stages are supported by intermediate CM and facilitation activities, tools and guidance that support the modeller in developing dedicated outputs.

While participative modelling has received little attention in the DES community, our experience has proved that it is enormously useful in practice. This is especially true for studies in healthcare character- 


\section{Participative and Facilitative conceptual modelling}

ized by many stakeholders with tacit knowledge of their part of the system and often multiple views and objectives. In such situation it is important to involve a range of stakeholders so that ultimately its findings are accepted. The timely engagement of a group of stakeholders in the study provides the opportunity to mould the study to their collective requirements that can also instil a sense of ownership of the study. Our experience from the obesity study supports our premise that a participative and facilitative CM framework makes it possible to involve a group of healthcare stakeholders in the study and can lead to the conceptual model outputs. Furthermore, this stakeholder involvement can indeed lead to a valid, credible, useful and feasible conceptual model.

Further research in the field of healthcare conceptual modelling and/or facilitative conceptual modelling would be beneficial to the modelling and simulation community and where possible others could adopt (and adapt if necessary) the approach laid out in this paper. Reflections on other modellers' experiences of the framework presented would be also appreciated.

\section{AKNOWLEDGEMENTS}

This study was funded by the UK Engineering and Physical Sciences Research Council (EPRSC) grant EP/E045871/1.

\section{REFERENCES}

Ackoff R, (1979). Resurrecting the future of operational research. The Journal of the Operational Research Society. 30(3). 189-199.

Andersen DF, Richardson GP and Vennix JAM, (1997). Group model building: adding more science to the craft. System Dynamics Review 13(2): 187-201.

Balci, O. (2010) Golden Rules of Verification, Validation, Testing, and Certification of Modeling and Simulation Applications.” SCS M\&S Magazine, Oct. 2010 Issue 4. Vista, CA: The Society for Modeling and Simulation International (SCS).

Balci O (2011) How to successfully conduct large-scale modeling and simulation Projects. In Proceedings of the 2011 Winter Simulation Conference, S. Jain, R.R. Creasey, J. Himmelspach, K.P. White, and M. Fu, eds. December 2011. Phoenix. AZ

Balci O, Arthur JD and Nance RE (2008) Accomplishing reuse with a simulation conceptual model. In Proceedings of the 2008 Winter Simulation Conference. S. J. Mason, R. R. Hill, L. Mönch, O. Rose, T. Jefferson, J. W. Fowler eds .Miami. FL.

Balci O and Nance RE (1985). Formulated problem verification as an explicit requirement of model credibility. Simulation. 45(2). 753-763.

Balci O and Ormsby W F (2007), Conceptual Modeling for Designing Large-Scale Simulations, Journal of Simulation 1(3) 175-186.

Banks J, Carson J, Nelson BL and Nicol D (2005) Discrete-Event System Simulation, Prentice-Hall, (4E) Blackett PM S (1950). Operational Research. Operational Research Quarterly (1950-1952) 1(1): 3-6. 


\section{Participative and Facilitative conceptual modelling}

Brade, Dirk. 2004. A Generalized Process for the Verification and Validation of Models and Simulation Results. Ph.D. Theses at the University of the Federal Armed Forces of Germany, Munich

Brailsford, S. C., T. Bolt, C. Connell, J. H. Klein and B. Patel (2009). Stakeholder engagement in health care simulation. Winter Simulation Conference. Austin, Texas, Winter Simulation Conference: 18401849 Austin. TX.

Brooks RJ and Tobias AM (1996). Choosing the best model: Level of detail, complexity and model performance. Math Comput Model. 24(4). 1-14.

Butland B, Jebb S, Kopelman P, Mcpherson K, Thomas S, Mardell J and Parry V, (2007). Foresight. Tackling obesities: future choices.PROJECT REPORT. 2nd edition, accessed 15 April 2010. Government Office for Science. UK

Büyükdamgaci G (2003). Process of organizational problem definition: How to evaluate and how to improve. Omega 31: 327-338.

Checkland P, (1999). Systems thinking systems practice. Wiley. Chichester. UK.

Checkland P and Scholes J (1999). Soft Systems Methodology in Action. Wiley. Chichester. UK.

Department Of Health (2004). The NHS Improvement Plan: Putting People at the Heart of Public Services. Publication. SERIES: Cm 6268 ISBN 0-10-162682-7. TSO. London. UK

Eldabi T, Paul RJ and Young T (2007). Simulation modelling in healthcare: reviewing legacies and investigating futures, Journal of the Operational Research Society. 58. 262-270.

Fone D, Hollinghurst S, Temple M, Round A, Lester N, Weightman A, Roberts K, Coyle E, Bevan G, and Palmer P (2003). Systematic review of the use and value of computer simulation modelling in population health and health care delivery. Journal of Public Health 25(4): 325-335.

Gunal and Pidd (2005) Simulation modelling for performance measurement in healthcare, In: M.E Kuhl, N.M. Steiger, F.B. Armstrong and J.A Joines (eds) Proceedings of the 2005 Winter Simulation Conference, Orlando, FL, USA, December 4-7, 2005. ACM: 2663-2667.

Henriksen JO (1988). One system, several perspectives, many models. In Proceedings of the 1988 Winter Simulation Conference. M. Abrams, P. Haigh, J Comfort. IEEE. Piscataway. NJ.

Franco LA and Montibeller G (2010). Facilitated modelling in operational research. European Journal of Operational Research. 205. 489-500

Grinyer PH (2000). A cognitive approach to group strategic decision taking: A discussion of evolved practice in the light of received research results. J Opl Res Soc 51: 21-35.

Jun JB, Jacobson SH, and Swisher JR (1999). Application of discrete-event simulation in health care clinics: A survey. Journal of the Operational Research Society 50(2): 109-123.

Kotiadis K (2007). Using soft systems methodology to determine the simulation study objectives. Journal of Simulation 1: 215-222.

Kotiadis K and Robinson S (2008). Conceptual modelling: Knowledge acquisition and model abstraction. Proceedings of the 2008 Winter Simulation Conference, S. J. Mason, R. R. Hill, L. Mönch, O. Rose, T. Jefferson, J. W. Fowler eds .Miami. FL.

Law AM (2007). Simulation modeling and analysis. McGraw-Hill. $4^{\mathrm{TH}}$ EDITION. Boston. MA

Lehaney B, Clarke SA and Paul RJ (1999). A case of an intervention in an outpatients department. Journal of the Operational Research Society 50: 877-891. 


\section{Participative and Facilitative conceptual modelling}

Lehaney B and Hlupic V (1995). Simulation modelling for resource allocation and planning in the health sector. Perspectives in Public Health 115(6): 382-385.

Lehaney B, and Paul RJ (1994). Using soft systems methodology to develop a simulation of outpatient services. Journal of the Royal Society for the Promotion of Health 114 (5): 248-251.

Lehaney B, and Paul RJ (1996). The use of soft systems methodology in the development of a simulation of out-patients services at Watford General Hospital. Journal of the Operational Research Society 47: 864-870.

Lowery JC (1994). Barriers to implementing simulation in health care. In Proceedings of the 1994 Winter Simulation Conference, Tew J.D, Mannivannan S, Sadowski D.A. and Seila A.F. (eds) December 11-14. 1994. Lake Buena Vista, FL, USA. ACM. 868-875.

Mingers J and Rosenhead J (2004). Problem structuring methods in action. European Journal of Operational Research. 152 (3). 530-555.

Nance RE (1994). The conical methodology and the evolution of simulation and development. Ann Opns Res. 53. 1-45.

National Institute For Health And Clinical Excellence. 2006. Obesity: guidance on the prevention, identification, assessment and management of overweight and obesity in adults and children. NICE clinical guideline 43. re-issued 29 January 2010. London. UK. National Institute for Health and Clinical Excellence

Nutt, P. (1986). "Tactics of Implementation." The Academy of Management Journal 29(2): 230-261.

Pace DK (1999) Development and documentation of a simulation conceptual model. In: Proceedings of the 1999 Fall Simulation Interoperability Workshop. (Accessed August 2005).

Pace DK (2000) Ideas about simulation conceptual model development. Johns Hopkins APL Tech Dig, 21, pp. 327-336.

KN Papamichail1, G Alves, S French, JB Yang and R Snowdon (2007) Facilitation practices in decision workshops, Journal of the Operational Research Society 58 (5), 614-632

Phillips LD and Phillips MC (1993). Facilitated work groups-Theory and practice. J Opl Res Soc 44 (6): 533-549.

Pidd, M. (1999). Just Modeling Through: A Rough Guide to Modeling. Interfaces 29(2): 118-132.

Pidd M (2007). Making sure you tackle the right problem: linking hard and soft methods in simulation practice. Proceedings of the 2007 Winter Simulation Conference, Washington D.C., Institute of Electrical and Electronic Engineers, Inc.

Pritsker AAB (1986). Model evolution: A rotary table case history. In Proceedings of the 1986 Winter Simulation Conference. J. Wilson, J. Henriksen And S. Roberts. Eds. IEEE. Piscataway. NJ.

Robinson S (2004). Simulation: The Practice of Model Development and Use. John Wiley \& Sons. Chichester. UK.

Robinson S (2008a). Conceptual modelling for simulation Part I: definition and requirements. Journal of the Operational Research Society 59(3): 278-290.

Robinson S (2008b). Conceptual modelling for simulation Part II: a framework for conceptual modelling.Journal of the Operational Research Society 59(3): 291-304. 


\section{Participative and Facilitative conceptual modelling}

Robinson S (2011).A framework for simulation conceptual modelling. In Conceptual modelling for discrete event simulation, S. Robinson, R. Brooks, K. Kotiadis, and DJ. Van Der Zee, Eds. CRC Press. Boca Raton, FL. 73-101.

Rosenhead J and Mingers J (2001). Rational Analysis for a problematic world revisited. Wiley. Chichester. UK

Rouwette EA J A, Vennix JAM and Mullekom TV (2002), Group model building effectiveness: a review of assessment studies. System Dynamics Review, 18: 5-45

Sargent RG (2001). Some approaches and paradigms for verifying and validating simulation models. In Proceedings of the 2001 Winter Simulation Conference. B.A Peters, J.S. Smith, D.J. Medeiros, M.W. Rohrer, Eds. December 2001. Arlington. VA.

Sargent RG (2008) Verification and validation of simulation models. In Proceedings of the 2008 Winter

Simulation Conference. S. J. Mason, R. R. Hill, L. Mönch, O. Rose, T. Jefferson, J. W. Fowler eds .December 2008. Miami. FL

Shannon RE (1975) Systems Simulation : The Art and Science, Prentice-Hall: Englewodd Cliffs, NJ.

Tako, A. A., Kotiadis, K., Vasilakis, C., Miras, A., \& le Roux, C. W. (2012). Modeling patient waiting times for an obesity service: a computer simulation study. submitted to Quality and Safety, Available from Loughborough University Institutional Repository, http://hdl.handle.net/2134/9330

The Nhs Information Centre Lifestyles Statistics.(2008). Statistics on Obesity, Physical Activity and Diet: England, 2008. The Information Centre. 25 February 2009.

van Der Zee DJ( 2007). Developing participative simulation models: Framing decomposition principles for joint understanding. Journal of Simulation. 1, 187-202.

van Der Zee DJ (2011). Developing participative simulation models: Framing decomposition principles for joint understanding. In Conceptual modelling for discrete event simulation, S. Robinson, R. Brooks, K. Kotiadis, and DJ. Van Der Zee, Eds. CRC Press. Boca Raton, FL. 103-132.

van Der Zee DJ, Kotiadis K, Tako AA, Pidd M, Balci O, Tolk A, Elder M (2010). Panel discussion: education on conceptual modelling for simulation - challenging the art. In Proceedings of the 2010 Winter Simulation Conference, B. Johansson, S. Jain, J. Montoya-Torres, J. Hugan, and E. Yücesan Eds. (Piscataway, New Jersey: Institute of Electrical and Electronics Engineers (IEEE), 290-304.

van Der Zee, D.J., Tolk, A., Pidd, M., Kotiadis, K., Tako, A., 2011, Education on Conceptual Modeling for Simulation - Beyond the Craft: A Summary of a Recent Expert Panel Discussion, 2010, Panel discussion: education on conceptual modelling for simulation - challenging the art, SCS Magazine 2(2), 93-102

van Der Zee DJ and van Der Vorst JGAJ (2005). A modelling framework for supply chain simulations: Opportunities for improved decision making. Decis Sci. 36. 65-95.

Vennix J A M (1999). Group model-building: tackling messy problems. System Dynamics Review 15(4): 379.

Vennix JAM (1996). Group Model-building: Facilitating Team Learning Using System Dynamics. Wiley. Chichester. UK

Vennix, J. A. M. and J. W. Gubbels (1992). "Knowledge elicitation in conceptual model building: A case study in modeling a regional Dutch health care system." European Journal of Operational Research 59(1): 85-101.

Vennix, J. A. M., J. W. Gubbels, D. Post and H. J. Poppen (1990). "A structured approach to knowledge elicitation in conceptual model building." System Dynamics Review 6(2): 194-208. 


\section{Participative and Facilitative conceptual modelling}

Willemain TR (1994). Insights of modelling from a dozen experts. Opns Res. 42. 413-222.

Wilson JCT (1981). Implementation of computer simulation projects in health care. J Opl Res Soc 32(9): 162-164.

Zeigler BP (1976). Theory of modeling and simulation. Wiley. New York

\section{FIGURES AND TABLES:}

Table 1: A Framework (package) for participative Conceptual Modelling (Stages, Activities, Tools and Deliverables)

\begin{tabular}{|c|c|c|c|c|}
\hline Stage and Purpose & CM Support Activities & $\begin{array}{l}\text { Facilitation Support Ac- } \\
\text { tivities }\end{array}$ & Tools & $\begin{array}{l}\text { CM outputs/ deliv- } \\
\text { erables }\end{array}$ \\
\hline $\begin{array}{l}\text { 1. Initiate Study } \\
\text { Purpose: } \\
\text { - Identify stake- } \\
\text { holder team } \\
\text { - Identify key prob- } \\
\text { lem situation(s) }\end{array}$ & $\begin{array}{l}\text { The modelling team under- } \\
\text { take: } \\
\text { - informal meetings } \\
\text { and/or } \\
\text { - on-site observations } \\
\text { and/or } \\
\text { - one-to-one interviews } \\
\text { with project champion and } \\
\text { key stakeholder(s), to ad- } \\
\text { dress preliminary infor- } \\
\text { mation needs }\end{array}$ & $\begin{array}{l}\text { Determine a list of key } \\
\text { stakeholders to be in- } \\
\text { volved in study and time- } \\
\text { scales. } \\
\text { Modelling team and } \\
\text { stakeholder team roles } \\
\text { are decided. }\end{array}$ & $\begin{array}{l}\text { Information Col- } \\
\text { lection Tool }\end{array}$ & $\begin{array}{l}\text { Preliminary under- } \\
\text { standing of the } \\
\text { problem situation }\end{array}$ \\
\hline $\begin{array}{l}\text { 1.a Pre-workshop } \\
\text { stage } \\
\text { Purpose: } \\
\text { Preparations for } \\
\text { Workshop } 1\end{array}$ & $\begin{array}{l}\text { Modelling team prepare } \\
\text { preliminary materials for } \\
\text { tools to be used in work- } \\
\text { shop } 1\end{array}$ & $\begin{array}{l}\text { Workshop } 1 \text { and } 2 \text { ven- } \\
\text { ues and time slots are de- } \\
\text { termined. } \\
\text { Stakeholders are invited } \\
\text { to workshops } \\
\text { Facilitator prepares for } \\
\text { the workshop } 1 \text {. }\end{array}$ & & \\
\hline $\begin{array}{l}\text { 2. Define system } \\
\text { (Workshop 1) } \\
\text { Purpose: } \\
\text { Agree on the prob- } \\
\text { lem situation and } \\
\text { the wider system, } \\
\text { within which it ex- } \\
\text { ists. }\end{array}$ & $\begin{array}{l}\text { Participating stakeholders } \\
\text { take part in a facilitated } \\
\text { workshop process to: } \\
\text { - Brainstorming problem } \\
\text { area (s) to be addressed } \\
\text { and identify study objec- } \\
\text { tives } \\
\text { - Define system boundaries }\end{array}$ & $\begin{array}{l}\text { During the workshop the } \\
\text { facilitator guides the } \\
\text { group of stakeholders } \\
\text { through the process by } \\
\text { proposing activities and } \\
\text { providing tools so they } \\
\text { design/determine the de- } \\
\text { liverables. }\end{array}$ & $\begin{array}{l}\text { Problem state- } \\
\text { ment form } \\
\text { CATWOE and } \\
\text { root definition } \\
\text { Care system } \\
\text { model }\end{array}$ & $\begin{array}{l}\text { General study ob- } \\
\text { jective(s) } \\
\text { A bounded system } \\
\text { within which the } \\
\text { problem to be ad- } \\
\text { dressed exists }\end{array}$ \\
\hline $\begin{array}{l}\text { 2.a Post work- } \\
\text { shop1/Pre-workshop } \\
2 \text { stage } \\
\text { Purpose: Dissemi- } \\
\text { nate workshop } 1 \\
\text { outputs and prepare } \\
\text { workshop } 2\end{array}$ & $\begin{array}{l}\text { Modelling team re-draw } \\
\text { tools \& disseminate work- } \\
\text { shop outputs to stakehold- } \\
\text { ers } \\
\text { Prepare preliminary materi- } \\
\text { als for tools used in work- } \\
\text { shop } 2\end{array}$ & $\begin{array}{l}\text { The modelling team li- } \\
\text { aises with the stakehold- } \\
\text { er team over correctness } \\
\text { of workshop } 1 \text { outputs. } \\
\text { Workshop } 2 \text { venue and } \\
\text { timeslot is confirmed. } \\
\text { The facilitator prepares } \\
\text { for workshop } 2\end{array}$ & & \\
\hline $\begin{array}{l}\text { 3. Specify concep- } \\
\text { tual model (Work- } \\
\text { shop 2) } \\
\text { Purpose: } \\
\text { Define specific ele- }\end{array}$ & $\begin{array}{l}\text { Participating stakeholders } \\
\text { take part in a facilitated } \\
\text { workshop process to: } \\
\text { - Put forward and agree on } \\
\text { performance measures to } \\
\text { address the problem iden- }\end{array}$ & $\begin{array}{l}\text { During the workshop the } \\
\text { facilitator guides the } \\
\text { group of stakeholders } \\
\text { through the process by } \\
\text { proposing activities and } \\
\text { providing tools so they }\end{array}$ & $\begin{array}{l}\text { Performance } \\
\text { measurement } \\
\text { model (PMM) } \\
\text { Study objectives } \\
\text { form }\end{array}$ & $\begin{array}{l}\text { Model inputs and } \\
\text { outputs and model } \\
\text { content } \\
\text { Model objectives }\end{array}$ \\
\hline
\end{tabular}


Participative and Facilitative conceptual modelling

\begin{tabular}{|c|c|c|c|c|}
\hline $\begin{array}{l}\text { ments of the concep- } \\
\text { tual model }\end{array}$ & $\begin{array}{l}\text { tified in workshop } 1 \\
\text { - Identify inputs, outputs } \\
\text { and model content } \\
\text { - Define the model objec- } \\
\text { tives } \\
\text { - Produce communicative } \\
\text { model (discuss model con- } \\
\text { tents, model scope and } \\
\text { level detail) } \\
\text { - Discuss responsibility for } \\
\text { data collection. }\end{array}$ & $\begin{array}{l}\text { design/determine the de- } \\
\text { liverables. }\end{array}$ & $\begin{array}{l}\text { Patient Flow dia- } \\
\text { gram }\end{array}$ & $\begin{array}{l}\text { A preliminary lists } \\
\text { of assumptions and } \\
\text { simplifications } \\
\text { A communicative } \\
\text { model } \\
\text { A list of data re- } \\
\text { quirements }\end{array}$ \\
\hline $\begin{array}{l}\text { 3.a Post workshop } 2 \\
\text { stage } \\
\text { Purpose: Dissemi- } \\
\text { nate workshop } 2 \\
\text { outputs and refine } \\
\text { conceptual model }\end{array}$ & $\begin{array}{l}\text { Modelling team prepare re- } \\
\text { port detailing: } \\
\text { - } \quad \text { Refined CM outputs } \\
\text { from stage } 2 \text {.a and stage } \\
3 \\
\text { - } \quad \text { Data requirements }\end{array}$ & $\begin{array}{l}\text { The modelling team li- } \\
\text { aises with the stakehold- } \\
\text { er team over correctness } \\
\text { of workshop } 2 \text { outputs. }\end{array}$ & & $\begin{array}{l}\text { An agreeable to all } \\
\text { (study participants) } \\
\text { and feasible con- } \\
\text { ceptual model de- } \\
\text { scribing DES study }\end{array}$ \\
\hline
\end{tabular}

Table 2 Descriptions of project team roles

\begin{tabular}{|c|c|}
\hline $\begin{array}{l}\text { Roles of project } \\
\text { team: }\end{array}$ & Description of each role: \\
\hline \multicolumn{2}{|l|}{ Modelling team } \\
\hline $\begin{array}{l}\text { The simulation } \\
\text { modeller (model } \\
\text { coder) }\end{array}$ & $\begin{array}{l}\text { Someone experienced in DES modelling, particularly in coding the } \\
\text { model. Is responsible in communicating the viability of transforming } \\
\text { the conceptual model into a computer model within the agreed } \\
\text { timeframe. Is responsible for validation and verification throughout } \\
\text { the simulation study. }\end{array}$ \\
\hline The recorder & $\begin{array}{l}\text { Take notes and generally observes the situation and is on hand to } \\
\text { provide the facilitator with assistance in organising the workshop } \\
\text { particularly in terms of pre-workshop (e.g. sorting agendas prelimi- } \\
\text { nary outputs etc) and post-workshop activities (e.g. disseminating the } \\
\text { output of workshops or chasing up data or information). Recording } \\
\text { equipment cannot replace this role if confidential information is dis- } \\
\text { cussed. Also if recording equipment is used then this role can safe- } \\
\text { guard in the event of an unexpected electronic failure. }\end{array}$ \\
\hline The facilitator & $\begin{array}{l}\text { A person that leads activities within a workshop with good facilita- } \\
\text { tion skills such as active listening, chart writing, managing group } \\
\text { dynamics and power shifts and reaching closure (Franco and } \\
\text { Montibeller, 2010). A workshop can be led by one or more facilita- } \\
\text { tors whose role is to enable the group to meet their workshop objec- } \\
\text { tives within the available timeframe by guiding the participants in } \\
\text { any activities undertaken, keeping the interaction among the partici- } \\
\text { pants relevant and at the centre of the room. }\end{array}$ \\
\hline \multicolumn{2}{|c|}{ Stakeholder team } \\
\hline The project & This person could be either someone enthusiastic about the study or \\
\hline
\end{tabular}




\begin{tabular}{|c|c|}
\hline champion & $\begin{array}{l}\text { the initiator of the study (Brailsford et al, 2009). He/she serves as a } \\
\text { link between the modelling team and the stakeholder team. The pro- } \\
\text { ject champion will motivate other stakeholders and help to organize } \\
\text { workshops. }\end{array}$ \\
\hline Key stakeholders & $\begin{array}{l}\text { People with tacit knowledge of the organisation involved and usually } \\
\text { with decision making power in the stakeholder organisation. }\end{array}$ \\
\hline $\begin{array}{l}\text { Other stakehold- } \\
\text { ers }\end{array}$ & People with tacit knowledge of the organisation. \\
\hline
\end{tabular}

Figure 1 An extract from detailed guidance on the CATWOE Tool facilitation

Facilitators should encourage participants to come up with a range of ideas and then narrow these down to the most suitable ones.

For help with generating each CATWOE element, some tips and ideas about what to think about are provided below:

C: Customers - the victims or beneficiaries that the system of interest serves.

In a healthcare study customers are normally the patients served by the particular healthcare organization or unit under study.

\section{CATWOE Definitions}

Customers: People with morbid obesity in the specified geographic area in the UK.

Actors: Various healthcare professionals specialising in the treatment of morbid obesity at the hospitals concerned.

Transformation: The provision of treatment to obese people is met, by designing and operating a care system that consists of clinical, managerial, and research activities.

Weltanschauung (World view): A belief that designing and operating a system of clinical, managerial, and research activities for providing care to morbidly obese people and for creating a framework for research is important in providing effective care for people with obesity.

Owners: The trust board at the London-based hospitals and the Specialised Commissioning Groups.

Environment: Funding for resources, changes in government targets, current public healthy living initiatives(e.g. eating five portions of fruits and vegetable a day, cycling to work), researchbased therapy and technological changes.

\section{Root Definition:}

A system owned by the trust board and the Specialised Commissioning Group operated by various healthcare professionals at London-based hospitals specialising in the treatment of obesity that support the bariatric care pathway in their jurisdiction by designing a system of clinical, managerial, and research activities in order to provide effective care for people with obesity whilst recognizing the constraints of funding for resources, changes in government targets, current public healthy living initiatives, research-based therapy and technological changes. 
Figure 2: CATWOE and Root Definition for a bariatric care system developed in a facilitated PartiSim study.

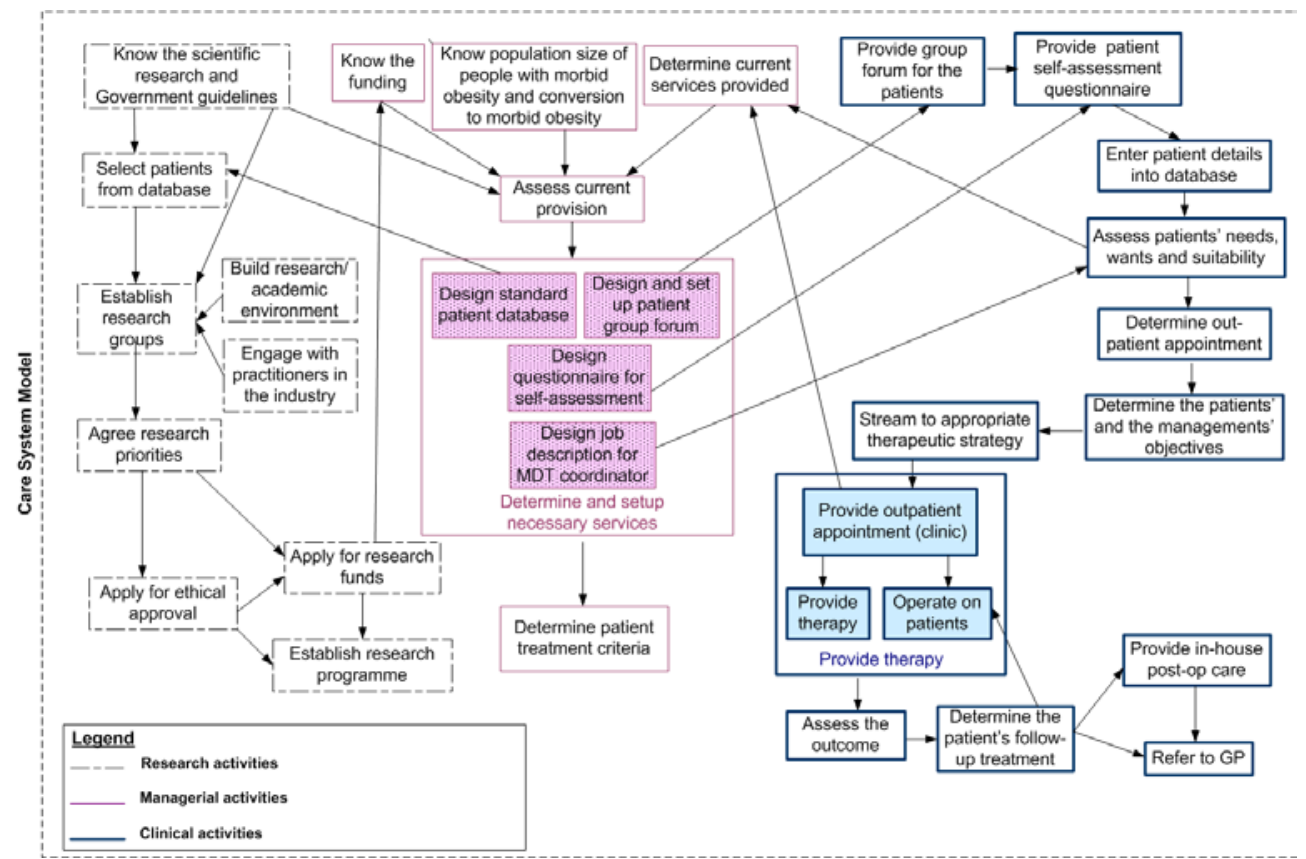

Figure 3: A Care System Model representing the research, managerial and clinical activities in the obesity care system

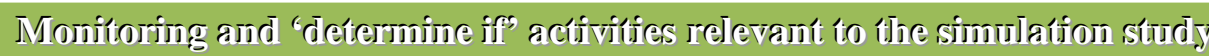

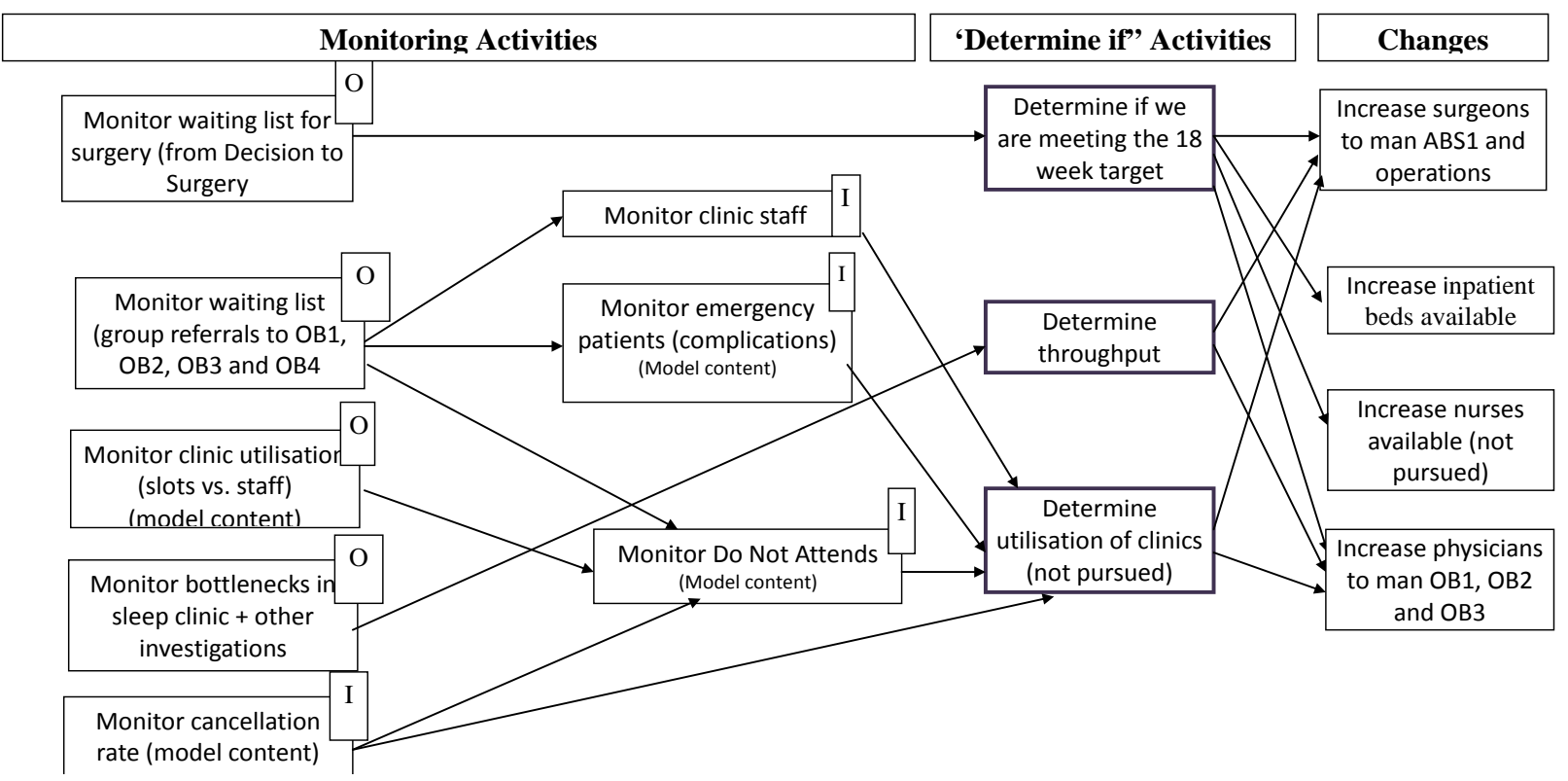

Figure 4: Performance Measurement model developed for the obesity care system. 
Table 3 SIMULATION STUDY OBJECTIVES

Objective 1: To explore reducing the waiting list for the surgical clinics, pharmacotherapy clinic and patient education by incrementally increasing the number of surgeons and physicians to a maximum of three and two respectively as well as reducing first time referrals.

Objective 2: To explore reducing the \% of patients that breach of the 18 week target by incrementally increasing the number of surgeons and physicians to a maximum of three and two respectively.

Objective 3: To explore how many bed days are required in post-operative care (following an operation) as a result of the increase in the number of surgeons (and corresponding surgical sessions) to a maximum of three surgeons.

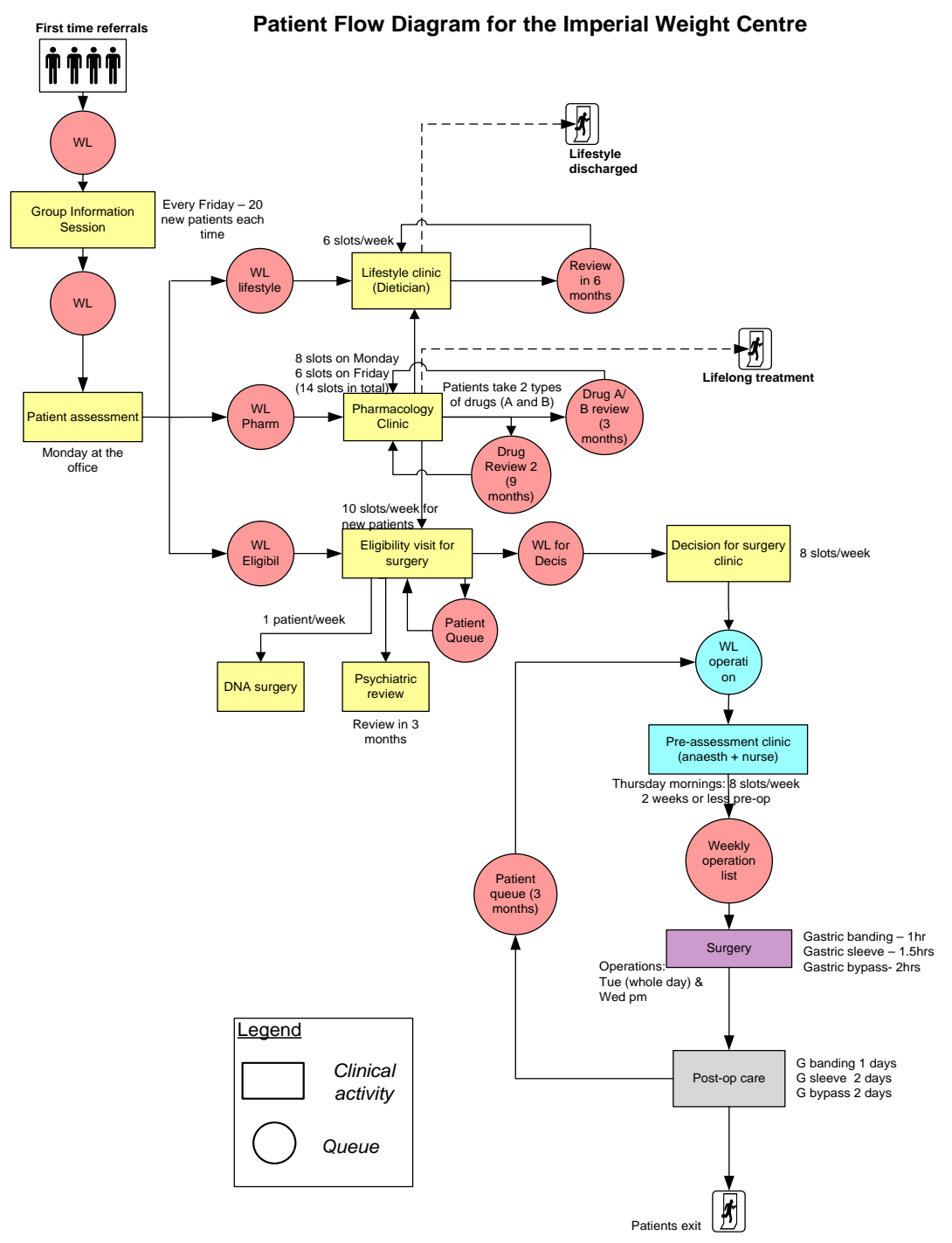

Figure 5: PFD diagram 
Participative and Facilitative conceptual modelling 